\title{
Optimization of urban spatial development against flooding and other climate risks, and wider sustainability objectives
}

\author{
Daniel Caparros-Midwood ${ }^{1}$, Richard Dawson ${ }^{1, a}$ and, Stuart Barr ${ }^{1}$ \\ ${ }^{1}$ School of Civil Engineering and Geosciences, Newcastle upon Tyne, NE1 7RU, UK
}

\begin{abstract}
A spatial optimization framework has been developed to help urban areas mitigate climate risks such as flooding and to curb resource use and greenhouse gas emissions. Measures required to address these issues often conflict with each other, for example more compact cities typically use less energy for transportation but increase runoff from high intensity rainfall events. Balancing potential trade-offs and maximizing synergies between these risks and vulnerabilities is therefore a multi-dimensional, spatial, challenge for urban planners. A spatial optimization framework is used to optimize the following objectives to minimize: (1) risk from heat waves; (2) risk from flooding; (3) the distance of new development to the current central business district; (4) urban sprawl to prevent increased travel costs; and (5) the development of green-space. The framework is applied to a real case study in the North East of England. From an initial configuration, alternative spatial configurations are tested against these objectives and the spatial pattern is evolved over successive generations to search for spatially optimum configurations. The resulting solutions provide planners with a range of robust spatial development patterns known to be best trade-offs which mitigate conflicts between risk and sustainability objectives.
\end{abstract}

\section{Introduction}

Rising populations, increased frequency of extreme events and actions to decarbonise are posing challenges for urban planners $[1,2,3]$. Indeed, it is expected that urban areas will become the foci of natural hazards over the next century, due to the increased likelihood of climate change induced hazards such inland flash floods, coastal flood and heat wave events that are a result of climatically driven heavier precipitation events, increased sea level rise and higher summer temperatures [4]. Critically, cities are themselves one of the major drivers of climate change, directly or indirectly producing $75 \%$ of global carbon emissions [5]. Therefore, in order to either mitigate and/or adapt to the potential impacts of climate change it is widely accepted that there is a need to move towards sustainable cities that are robustly adapted to natural (and other) hazards, while simultaneously reducing energy and resource usage to mitigate further climatic change [6].

This transition to more sustainable configuration may lead to conflicts between long term sustainability objectives that lead to robust cities of the future and short term sustainability aims such as mitigating energy use and emissions [6]. For example, the last decade of spatial planning policy in Europe has focused almost exclusively on mitigation of climate change through urban intensification [7], as denser cities are typically associated with lower transport energy use $[8,9]$. However, urban densification has been found to intensify urban heat islands, increase flood risk, due to reduced surface permeability, and lead to poor health outcomes for residents $[3,10,11]$. Therefore it is essential that spatial planners consider both short and long term multiple sustainability objectives when designing the cities of the future.

Within the spatial planning process, it is normal for sustainability appraisals to consider potential conflicts between different sustainability objectives. However, this is often performed in a highly subjective manner with little analytical consideration of how multiple negative impacts in totality may negate the ability to coherently spatially design the cities of the future [12]. However, there is considerable evidence that analytical methods such as spatial optimisation can be successfully employed in the planning of individual urban infrastructure such as water supply, land use and transport infrastructure [13, $14,15,16,17,18]$.

To address this challenge, this paper investigates the utility of spatial optimisation to identify spatial development strategies that are optimised against one, or many, objectives. The framework is novel in that it couples simulated annealing with Pareto-optimization to identify optimal urban spatial development strategies for different combinations of multiple sustainability objectives. A case study in Middlesbrough a town in the North East of England is used to demonstrate how spatial Pareto-optimization can be employed to derive spatial development patterns that are sensitive to climate induced hazards such as heatwave and flood risk, whilst also

\footnotetext{
${ }^{a}$ Corresponding author: richard.dawson@newcastle.ac.uk
} 
contributing to other sustainability objectives such as reducing greenhouse gas emissions, limiting urban sprawl and protecting green space.

\section{Methodology}

\subsection{Simulated annealing approach to spatial optimisation}

A simulated annealing optimisation algorithm is used here. This determines optimal solutions to combinatorial optimisation problems by utilising a probability based acceptance criteria to intelligently search iteratively for better solutions [19]. Simulated annealing has been used for several spatial optimisation applications, including resource allocation, ground water allocation and forest planning $[14,16,20]$.

Figure 1 presents the flow diagram of the simulated algorithm utilised for a single objective. The procedure begins with an initial spatial configuration of development (either a random or current spatial configuration) that becomes the current configuration, $D_{n}$, and an initial best configuration, $D_{b}$. The performance of the spatial configuration is evaluated against the objective functions $f_{\text {risk }}$ and $f_{\text {dist }}$ to give a measure of $F$ which is initially set as the current $\left(f_{n}\right)$ and best $\left(f_{b}\right)$ fitness values.

In simulated annealing, iteration is performed while the temperature variable $T$ exceeds $T_{\text {end }}$. During each iterative step an existing development site $d_{j} \in D$ is randomly moved within an 8-cell spatial Moore neighbourhood. This forms a new spatial development configuration, $D_{n+1}$, which is then evaluated to determine its fitness value $F$ which is stored as $f_{n+1}$. The current and new configurations are then compared based on their respective fitness values. If the performance of $D_{n+1}$, $f_{n+1}$, is found to be superior, it replaces $D_{n}, f_{n}$ and $f_{b}$ is set to $f_{n+1}$.

However, even if the solution is inferior it can still be accepted on the basis of the Thermopolis equation:

$e^{-\Delta / T}>R(0,1)$

where $\Delta$ is the difference between $f_{n}$ and $f_{n+1}$, while $R$ represents a random float value between 0 and 1 . The ability to accept inferior performing solutions on the basis of Equation 2 allows simulated annealing to be used to evaluate a wide range of spatial development patterns which prevents the algorithm converging on seemingly spatially-local non-global optimal development configurations.

Throughout the operation the best performing development pattern is retained as $D_{b}, f_{b}$. At the end of each iteration the temperature variable, $T$, is decreased by a cooling factor $C$ :

$T_{i+1}=T_{i} \times C$

where $0<C<1$ (in many simulated annealing applications $C$ is set between 0.8 and 0.98 [14]. As $T$ decreases the Thermopolis equation restricts acceptance to only superior performing spatial layouts with the intention of converging on the solution which is globally optimum throughout the entire range of possible spatial development patterns. The algorithm is repeated for a user defined number of, $m$, iterations, where at the start of each iteration $D_{n}, f_{n}$ are replaced by $D_{b}$ and $f_{b}$ to assist convergence to a global optima.

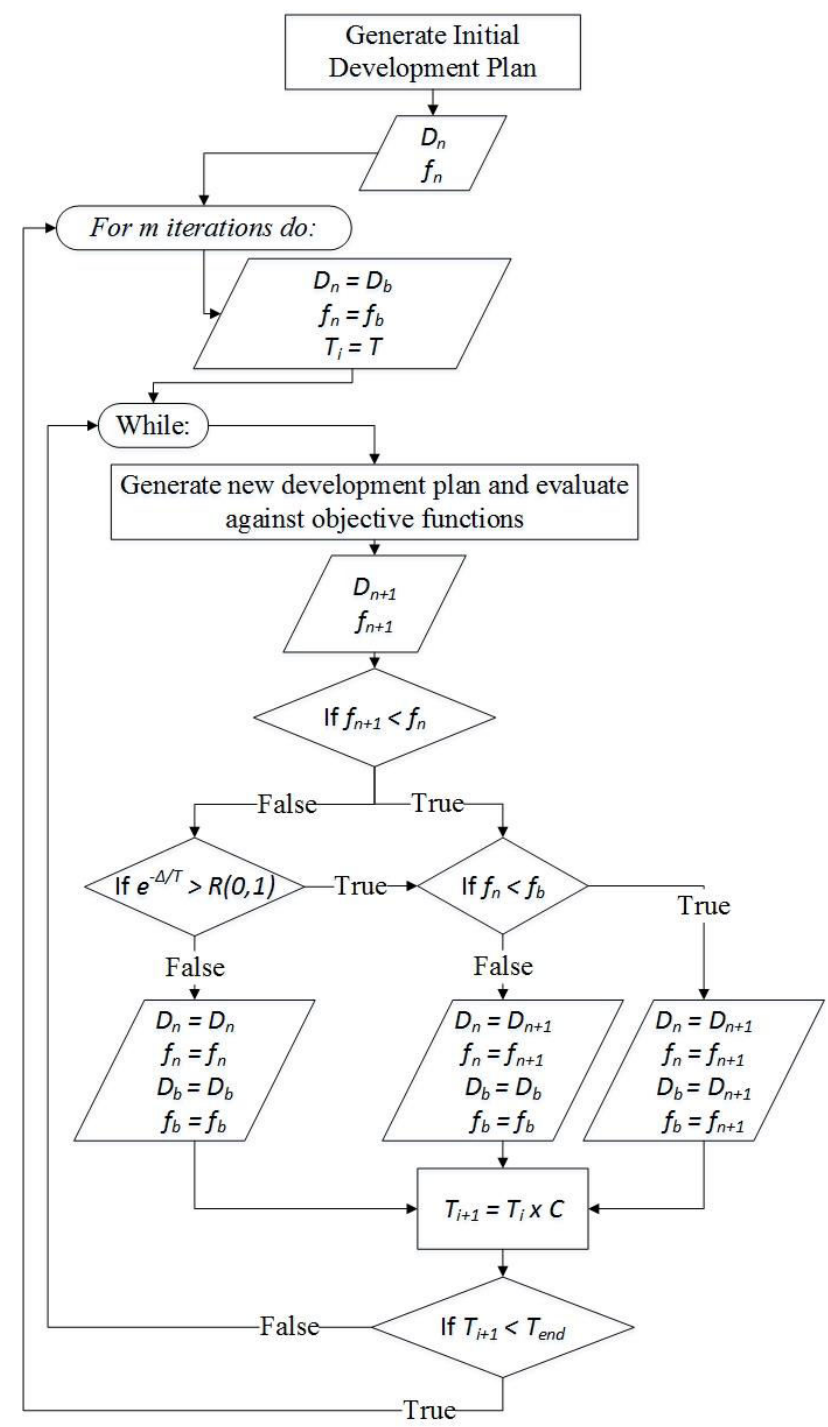

Figure 1. Methodological framework of the inter-disciplinary approach [21].

\subsection{Multi-objective optimisation}

In order to accommodate multiple objectives into the optimisation procedure a weighted methodology is employed to generate a composite fitness function calculated by:

$F=w_{\text {risk }} f_{\text {risk }}+w_{\text {dist }} f_{\text {dist }}$

where $w_{\text {risk }}$ and $w_{\text {dist }}$ represent weights assigned to each objective function. Within this weighted spatial optimisation approach the iterative terms $f_{b}, f_{n}$ and $f_{n+1}$ are normalised between 0 and 1 [22], which in turn 
requires knowledge of the possible maximum and minimum performance in each objective.

Multi-objective optimisation allows one to explore a wide range of potential optimal solutions that vary as a function of the individual objectives. Such a set of optimised solutions will itself have a sub-set of solutions that are better in terms of the combined objectives than others. In order to recognise such a sub-set a search algorithm to identify Pareto-optimal solutions has been employed [13, 15, 22, 23] which generates a set of solutions known as best trade-off solutions to which further cost-benefit analysis can be applied to derive a trade-off curve which displays the decision boundary of the best sub-set of possible solutions [13].

In order to apply a Pareto-optimal approach the composite function of Equation 4 is replaced by an evaluation of both objective functions $f_{\text {risk }}, f_{\text {dist }}$ during each iteration of the simulated annealing algorithm. If new configurations perform better in both objectives then the solution is accepted as $D_{n}$ and stored in a solutions list. Otherwise, $\Delta$ is calculated by the proportional difference in performance for both objectives for the purposes of the Thermopolis equation.

Once the simulated annealing algorithm is complete, solutions in the solution list are subject to a nondominated sorting procedure to extract Pareto-optimal solutions using the algorithm developed by [24], where Pareto-optimal solutions are determined based on the concept of domination. For $M$ objective functions a solution $x^{(1)}$ is said to dominate solution $x^{(2)}$ if:

1. The solution $x^{(1)}$ is no worse than $x^{(2)}$ in all objectives; $f_{j}\left(x^{(1)}\right) \leq f_{j}\left(x^{(2)}\right)$ for all $j=1,2, \ldots, M$, and;

2. The solution $x^{(1)}$ is strictly better than $x^{(2)}$ in at least one objective; $f_{j}^{-}\left(x^{(1)}\right)<f_{j}^{-}\left(x^{(2)}\right)$ for at least one $\bar{j} \in\{1,2, \ldots, M\}$.

In the context of this work, Pareto-optimal spatial configurations are extracted where no other spatial configuration performs better in one or more objective functions.

\section{Case Study}

To test the spatial optimisation framework developed it was applied to case study within Middlesbrough, a large town located in the North East of the UK (Figure 2). Middlesbrough has a land area of $54.55 \mathrm{~km}^{2}, 63 \%$ of which is classified as urban and the
2011 census recorded a population of 138,400 [25]. Population projections estimate an increase in population of 4,880 by 2020 . Therefore in order to accommodate this increase in population effectively, Middlesbrough's local development framework [26] recognises that there is a need to identify suitable areas for new residential development.

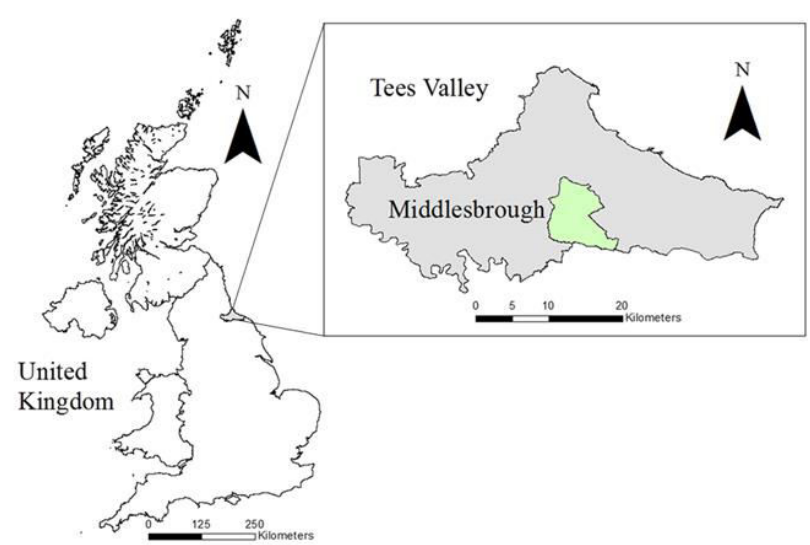

Figure 2. Location of the case study site, Middlesbrough, in the North East of England.

The local development framework sustainability appraisal developed by Middlesbrough council acknowledges potential conflicts between localised sustainability objectives during the appropriating of new residential development [27]. For example it is recognised that new development may lead to more private transport emissions which conflicts with the aim to curb air pollution over the area. Thus, tools that help planners understand how such conflicts can be minimised with respect to future urban development is of considerable interest.

Table 1 shows how the objectives of the regional spatial strategy for the North East [28] relate and map to those considered in this paper. In this case study of Middlesbrough the aim is to derive a suite of optimised residential development sites that can be compared to those that have been suggested by Middlesbrough council. Consideration of Middlesbrough's plans, was complemented by a wider review of academic and other local and national government sustainability priorities (including [29, 30, 31, 32, 33]) were used to identify five sustainability objectives on the basis that they are used in the local and national planning objectives, cover risk management and sustainability issues, and can be spatially parameterised. The five selected objectives are introduced below. 


\begin{tabular}{lll}
\hline $\begin{array}{l}\text { Framework } \\
\text { Sustainability Objective }\end{array}$ & Objective function & $\begin{array}{l}\text { Corresponding Spatial Strategy } \\
\text { Sustainability Objectives }\end{array}$ \\
\hline $\begin{array}{l}\text { Minimise risk from } \\
\text { flooding }\end{array}$ & Minimize: $f_{\text {flood }}=10^{0} \sum\left(d_{i j}=z_{i j}^{100}\right)+10^{-1} \sum\left(d_{i j}=z_{i j}^{1000}-z_{i j}^{100}\right)$ & $\begin{array}{l}\text { Reduce the risk of flooding and } \\
\text { SA14 } \\
\text { the resulting detriment to people } \\
\text { and property. }\end{array}$ \\
$\begin{array}{l}\text { Minimise risk from } \\
\text { climate induced heat } \\
\text { hazards }\end{array}$ & Minimize: $f_{\text {heat }}=\sum h_{i j}^{2020}-\sum h_{i j}^{2010}$ & SA13 $\begin{array}{l}\text { Reduce impacts of heat risks } \\
\text { from future climate change. }\end{array}$ \\
$\begin{array}{l}\text { Minimise greenhouse } \\
\text { gas emissions of } \\
\text { commute between } \\
\text { homes and businesses }\end{array}$ & Minimize: $f_{\text {dist }}=\operatorname{Min}\left(P\left(d_{i j}, c_{i j}, R\right) \forall c_{i j} \wedge d_{i j} \in D\right)$ & SA11 $\begin{array}{l}\text { To ensure good local air quality } \\
\text { for all. }\end{array}$ \\
$\begin{array}{l}\text { Encourage compact } \\
\text { city development by } \\
\text { minimising distance to Minimize: } f_{s p r a w l}=\sum d_{i j} \neq u_{i j} \forall d_{i j} \in D \\
\text { existing development }\end{array}$ & SA4 & $\begin{array}{l}\text { Ensure accessibility for all to } \\
\text { job facilities, goods and services } \\
\text { across the borough. }\end{array}$ \\
(5) $\begin{array}{l}\text { Avoid development of } \\
\text { green-space }\end{array}$ Minimize: $d_{i j}=g_{i j}$ & SA10 $\begin{array}{l}\text { To protect and enhance local } \\
\text { distinctiveness of the Borough's } \\
\text { urban and rural landscape. }\end{array}$ \\
\hline
\end{tabular}

Table 1. Sustainability objectives incorporated within the spatial optimisation framework and their corresponding sustainability objective from the spatial development strategy [31].

\subsubsection{Minimizing flood risk}

Flood was optimized on the basis of minimizing the objective function $f_{\text {flood }}$ which considers development within the 1 in 100 and 1 in 1,000 year flood zones where $z_{i j}^{n}$ in Objective 1 is the spatial grid representing the 1 in $n$ year flood zone. Floodzones shown in Figure 3 a were sourced from the UK's Environmental Agency's (EA) Flood zone maps. A full depth-probability grid would provide a richer and more accurate analysis of impacts, but these two boundaries are used as they are the thresholds defined by planning policy in England for different types of infrastructure and development choices [34].

\subsubsection{Minimizing risk from heatwaves}

Input data for the spatial heat hazard grid (Figure 3b) were derived from analysis of the medium emissions scenario of the UKCP09 climate projections [35]. The grid, $h_{i j}^{\text {year }}$, is calculated relative to current conditions. These are initially generated at a spatial resolution of $25 \mathrm{~km}$ for 30 -year time periods. In order to obtain a better spatial resolution and also to obtain direct measurements of estimated daily maximum and minimum daily temperatures a spatial weather generator was employed [36]. The spatial weather generator is a recent extension of the a-spatial weather generator that has been widely employed in several UK heat and heat wave impact studies [37, 38]. From the daily data-sets generated the mean annual frequency of heat wave events (defined as two consecutive days of temperatures in excess of $28^{\circ} \mathrm{C}$ with an intervening night temperature above $15^{\circ} \mathrm{C}$ ) for the 2020 s period at the 90 th percentile were extracted and normalised over the study area. Given the size of Middlesbrough there is limited variation in heat hazard across the city.

\subsubsection{Minimizing greenhouse gas emissions from transport}

Objective 3 was realised through optimizing an accessibility measure to areas of employment and services, namely distance of new development to the current Central Business District (CBD) with the reduction of commuting acting as a proxy for reducing transport emissions. An accessibility measure is used as they have been reported to be more strongly related to vehicle miles travelled than other measures such as compaction [39]. The optimization attempts to minimize the objective function $f_{\text {dist }}$ which is expressed by the average shortest path, $P()$, between proposed development sites, $d_{i j}$, and a point designated as a CBD centroid, $c_{i j}$, over a road network, $R$. Middlesbrough's CBD, $c_{i j}$, was represented by centroid of Town Centre Boundary as defined by Middlesbrough Council's Local Development Framework whilst the road network was represented by all major roads in the Ordnance Survey (the UK's national mapping agency) Meridian 2 dataset (Figure 3c).

\subsubsection{Minimizing urban sprawl}

Objective 4 was optimized on the basis of ensuring new development is within existing urban borders, $u_{i j}$, and characterized by the objective function $f_{\text {sprawl }}$. The current urban extent, Figure 3d, was extracted and rasterized from Ordnance Survey Meridian 2 Developed Land Use Areas (DLUA).

\subsubsection{Minimizing use of green space}

A spatial constraint on the selection of solutions in the form of $d_{i j} \neq g_{i j} \forall d_{i j} \in D$, where $g_{j}$ are the spatial 


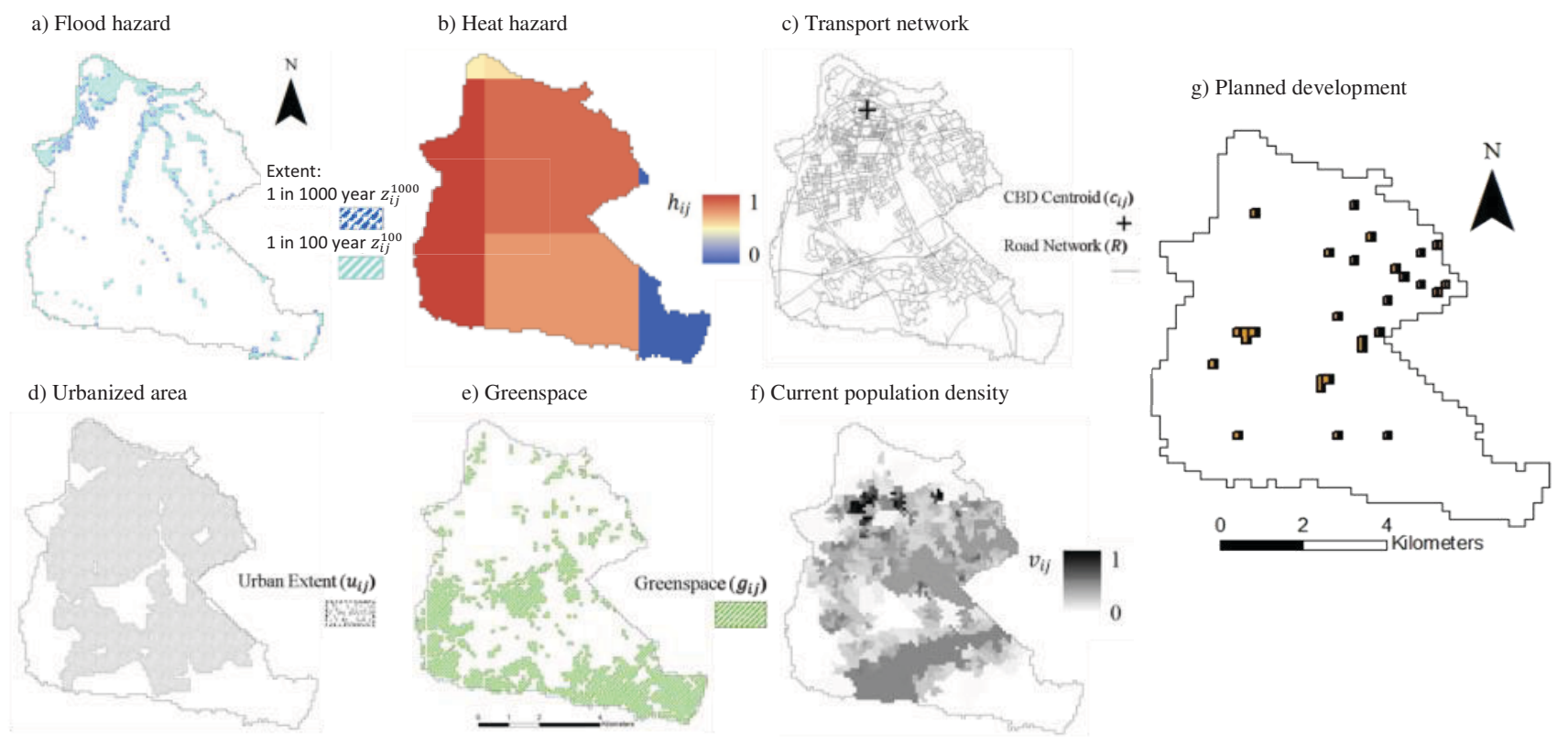

Figure 3. Spatial input datasets for the Middlesbrough case study showing: (a) the 1 in 100 and 1 in 1000 year floodplain; (b) heat hazard; (c) the transport network and location of the central business district centroid; (d) current location of urbanised area; (e) the location of greenspace; (f) population vulnerability; and, (g) the location of planned future development.

locations (cells) of green space (see Figure 3e). Greenspace in Middleborough, $g_{i j}$, was extracted from Ordnance Survey MasterMap topographic data by identifying features from the 'Natural' theme.

\subsubsection{Population vulnerability}

The 2011 census data [40] was used to extract population figures at lower super output area (a UK census sub-ward geography averaging approximately 1,500 people). These figures were then used to form the population vulnerability, shown as density per hectare data-set in Figure 3f.

All datasets were converted to a $100 \mathrm{~m}$ raster spatial grid. The initial plans for future residential development in Middlesbrough was digitised from the local council's spatial plans [27] is shown in Figure $3 \mathrm{~g}$ and provides a baseline for comparing with the optimal strategies identified by the algorithm below. The 4,880 increase in population by 2020 that is forecast for Middlesbrough is assumed to be distributed evenly over the 26 residential development sites set out by the proposals.

\section{Results}

\subsection{Improvement on current plan}

The optimization algorithm identifies many strategies that outperform the current development proposals against all objectives. The algorithm improves upon $f_{\text {heat }} f_{\text {dist }}$ and $f_{\text {sprawl }}$ in over $65 \%$ of the strategies identified. Moreover, the algorithm is also able to identify strategies that improve upon the current plan across all sustainability objectives, demonstrating potential to significantly improve upon the current plan in the context of these sustainability objectives.

\subsection{Tradeoffs between flood risk}

Figures 4 and 5 show some results of the optimization framework plotted against the normalized performances of Pareto-optimal fronts and the sub-set of solutions that are optimal for more than one sustainability objective. The performance of the current development plan [27] is highlighted for comparison. Table 2 summarizes the best performance between two objectives.

\begin{tabular}{l|c|c|c|c}
\hline \multicolumn{1}{c|}{ Conflict } & $\min ()$ & Min & Median & Max \\
& & \multicolumn{3}{|c}{ (Normalized) } \\
\hline \multirow{2}{*}{$f_{\text {heat }} \vee f_{\text {flood }}$} & $f_{\text {flood }}$ & $0(0)$ & $288(0.32)$ & $416(0.46)$ \\
& $f_{\text {heat }}$ & $3575(0)$ & $3642(0.11)$ & $3738(0.26)$ \\
\hline \multirow{2}{*}{$f_{\text {flood }} \vee f_{\text {dist }}$} & $f_{\text {flood }}$ & $0(0)$ & $128(0.14)$ & $512(0.57)$ \\
\hline \multirow{2}{*}{$f_{\text {flood }} \vee f_{\text {sprawl }}$} & $f_{\text {dist }}$ & $2901(0)$ & $3097(0.01)$ & $4084(0.42)$ \\
\hline & $f_{\text {flood }}$ & $0(0)$ & $96(0.11)$ & $128(0.14)$ \\
& $f_{\text {sprawl }}$ & $0(0)$ & $6(0.04)$ & $9.3(0.13)$ \\
\hline
\end{tabular}

Table 2. Summary of the solutions found for different tradeoffs between flood risk and other objectives.

Minimizing $f_{\text {flood }}$ is shown to conflict with reducing $f_{\text {heat }}$ and $f_{\text {dist }}$. The conflict with $f_{\text {heat }}$ occurs as low density areas coincide with flood risk areas in the north of the study area, whilst the conflict with $f_{\text {dist }}$ occurs against due to the presence of several flood zones in close proximity to the CBD. The conflict between $f_{\text {flood }}$ and $f_{\text {sprawl }}$ (not shown) is minor as there are many areas within the urban extent which are away from flood zone areas. The discrete coverage of the solution space in Figures 4 and 5 is because flood risk is parameterized in three discrete values: 1 in 100 floodplain, 1 in 1000 year floodplain and areas of no flood risk. The trade-off curve that emerges from the optimization allows a planner to explore the costs of improving a particular objective. 
Table 2 compares the extremes of these trade-offs, for example from the set of best solutions, $S_{b}$, achieving $\min \left(f_{\text {heat }}\right) \in S_{b}$ leads to normalized performance in $f_{\text {flood }}$ of 0.46 .

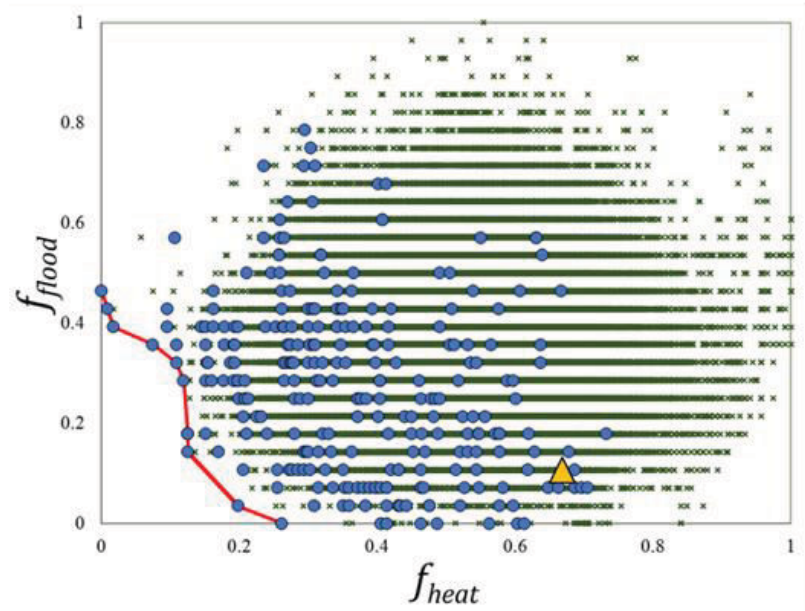

Figure 4. The tradeoff space, and pareto front, for flood and heat risk objectives. The small points are spatial solutions that are analysed, the large points show a solution that is optimal against one or more objectives. The triangle shows the current Middlesbrough development plan.

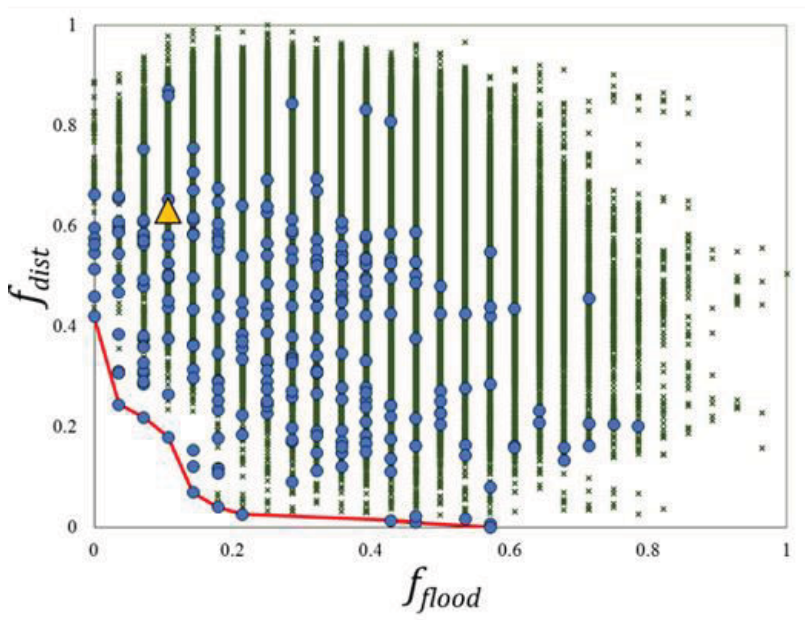

Figure 5. The tradeoff space, and pareto front, for flood and community distance objectives. The small points are spatial solutions that are analysed, the large points show a solution that is optimal against one or more objectives. The triangle shows the current Middlesbrough development plan.

The results (not shown) also demonstrate tradeoffs between $f_{\text {heat }}$ and both $f_{\text {dist }}$ and $f_{\text {sprawl }}$ - for example $\min \left(f_{\text {heat }}\right) \in S_{b}$ can only be achieved with $f_{\text {dist }}=0.59$ and $f_{\text {sprawl }}=0.5$ at best, whereas $f_{\text {heat }}=0.63$ and 0.49 for $\min \left(f_{\text {dist }}\right) \in S_{b}$, and $\min \left(f_{\text {sprawl }}\right) \in S_{b}$ respectively. This is because areas close to the CBD and within the current urban extent have higher population densities, which in turn lead to higher heat risks.

Interestingly, solutions that are optimal for more than one objective seem to generally perform reasonably well against others. Thus, planners selecting any Paretooptimal solution would likely be closer to a best trade-off in terms of many other objectives as the majority of the multi-objective Pareto-optimal solutions outperform the councils own development plan.

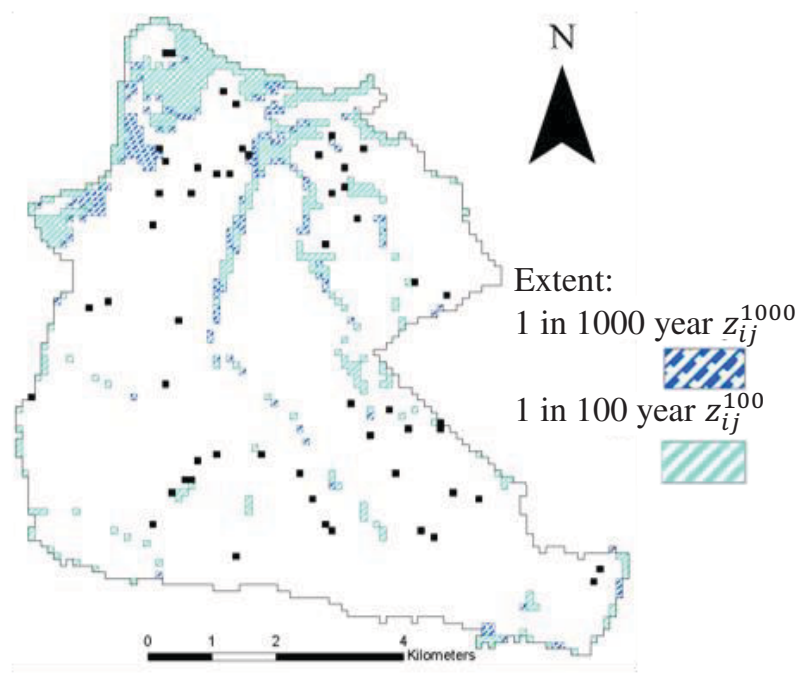

Figure 6. The best performing spatial development strategy (new development indicated by black raster cells) across all other objectives from the subset of best solutions that minimise $f_{\text {flood. }}$.

\subsection{Multi-objective strategies}

The analysis can be used to explore societal preferences and planning priorities. In Figure 7, the risk objectives, and the sustainability objectives are aggregated and the tradeoff between the two explored. The spatial developments strategies that provide a best outcome if a preference is made to prioritise risk management, or sustainability measures, or an equal balance of the two issues, are shown in Figure 8.

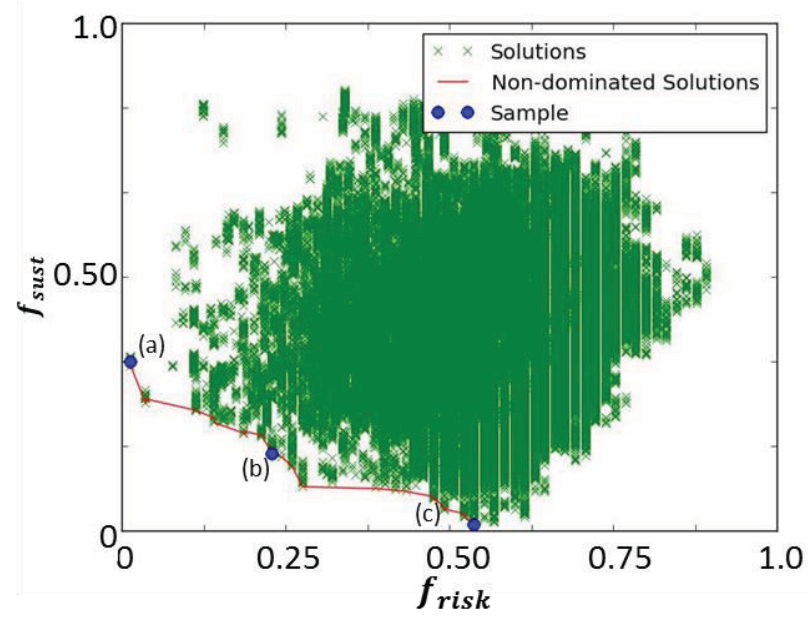

Figure 7. Pareto-optimal spatial configurations of the risk objectives compared against the sustainability objectives for the Middlesbrough case study. The selected solutions on the Pareto front correspond to the spatial strategies shown in Figure 8. 
(a)

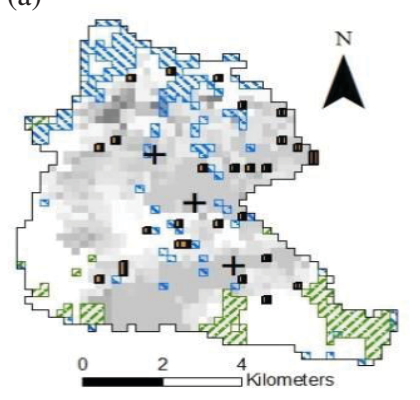

(b)

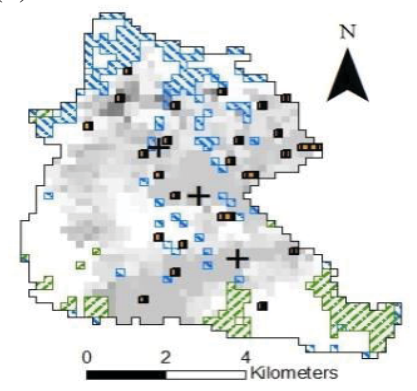

(c)

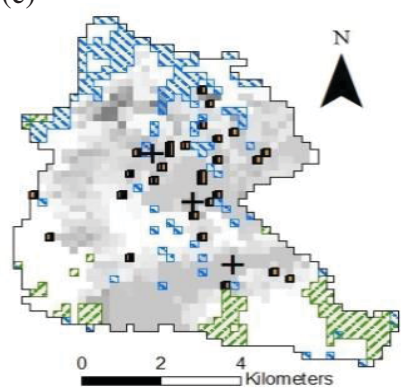

\section{Floodplain \\ Green space CBD centroid New development}

\section{Conclusion}

There is a need to reconfigure urban areas increase their resilience to flooding, heating and other climate induced hazards, whilst achieving other sustainability objectives such as reduced greenhouse gas emissions. However, the complexity of addressing so many objectives - often competing with each other - requires a rational and transparent approach to identify these and make choices about prioritising tradeoffs.

With this in mind, this paper has introduced a spatial optimization approach that is shown, through demonstration on a town in Britain, to provide planners with information on tradeoffs and conflicts between planning objectives. The results, and the diagnostic information contained within them, provides an evidence basis to help decision makers to better meet multiple sustainability objectives when developing long term urban development strategies. The application to Middlesbrough shows the method can identify development patterns that are not only improved in terms of flood risk but can additionally improve all other sustainability objectives that are considered here.

The results should be considered within the political and analytical aspects of decision making, and further qualitative and quantitative analysis can be applied to develop a final development plan. For example, reweighting priorities between risk management or sustainability criteria changes the optimal spatial patterns.

\section{Acknowledgments}

The work was funded the UK Engineering and Physical Sciences Research Council (ESPRC), grant reference EP/H003630/1.

\section{References}

1. UN (United Nations). 2011, "World Urbanization Prospects: The 2011 Revision Highlights", New York.

2. Mitchell, J., 1999, "Natural disasters in the context of mega-cities": Mitchell, (eds.), Crucibles of Hazard: Megacities and Disasters in Transition, Brookings Institute, Washington, p.15-55.
3. Hunt, A. and P. Watkiss, 2010, "Climate change impacts and adaptation in cities: a review of the literature", Climatic Change, 104(1), p. 13-49.

4. IPCC (International Panel on Climate Change) (2013). Summary for Policymakers. In: Climate Change 2013: The Physical Science Basis. Contribution of Working Group I to the Fifth Assessment Report of the Intergovernmental Panel on Climate Change. Cambridge University Press: Cambridge, United Kingdom and New York, NY, USA.

5. UN-Habitat (United Nations Human Settlements Programme), 2007, "Enhancing Urban Safety and Security”, Global Report on Human Settlements, Earthscan, London.

6. Dawson, R. J., 2011, "Potential pitfalls on the transition to more sustainable cities and how they might be avoided", Carbon Management, 2(2), p.175-188.

7. Biesbroek, G. R., R. J. Swart, T. R. Carter, C. Cowan, T. Henrichs, H. Mela, M.D. Morecroft, et al., 2010, "Europe adapts to climate change: Comparing National Adaptation Strategies", Global Environmental Change, 20(3): 440-50.

8. Newman, P. and J.R. Kenworthy, 1989, Cities and automobile dependence: a sourcebook. Gower, Aldershot.

9. Williams, K., E. Burton, and M. Jenks, 2000, “Achieving Sustainable Urban Form: Conclusions", in Williams K, E. Burton, M. Jenks, (ed.), Achieving Sustainable Urban Form, Routledge, London, p. 347-55.

10. Melia, S., G. Parkhurst, and H. Barton, 2012, "The Paradox of Intensification", Journal of Transport Policy, 18(1), p. 46-52.

11. Newton, P.W., P. Newman, P.C.L. Manins, R. Simpson and N. Smith, 1997, Reshaping cities for a more sustainable future: exploring the link between urban form, air quality, energy and greenhouse gas emissions, Australian Housing and Urban Research Institute, Melbourne.

12. Dawson, R. J. (2007). Re-engineering cities: A framework for adaptation to global change. Philosophical

Transactions of the Royal Society Special issue on Visions of the Future, 365(1861), 3085-3098. doi: 10.1098/rsta.2007.0008

13. Prasad, T. D., and N. S. Park, 2004, Multiobjective genetic algorithms for design of water distribution networks", $J$. Water Resour. Plan. Manage., 130(1), p. 73-82.

14. Aerts, J. and G. Heuvelink, 2002, "Using simulated annealing for resource allocation", International Journal of Geographic Information Science, 16(6), p. 517-87.

15. Vamvakeridou-Lyroudia, L. S., G. A. Walters, and D. A. Savic, 2005, "Fuzzy Multiobjective Optimization of Water Distribution", Journal of Water Resources Planning and Management, 131(6), p. 467-76. 
16. Sidiropoulos, E. and D. Fotakis, 2009, "Cell-based genetic algorithm and simulated annealing for spatial groundwater allocation", WSEAS Transactions on Environment and Development, 5(4), p. 351-360.

17. Ligmann-zielinska, A., R. Church, and P. Jankowski, 2005, "Sustainable urban land use allocation with spatial optimization" in Conference Proceedings. The 8th ICA Workshop on Generalisation and Multiple Representation, p. 1-18.

18. Shimamoto, H., N. Murayama, A. Fujiwara and J. Zhang, 2010, "Evaluation of Bus Network using a Transit Network Optimisation - Case Study on Hiroshima City Bus Network", 12th World Conference for Transportation Research, p. 1-24.

19. Kirkpatrick, S., C.D. Gelatt, and M.P. Vecchi, 1983, "Optimization by simulated annealing", Science, 220(4598), p. 671-80.

20. Lind, T., 2000, "Strategic forestry planning - evaluation of variable spatial aggregations and forest landscapes", Ph.D. thesis, Acta Universitatis Acriculturae Sueciae Silvestria, 149(28).

21. Caparros-Midwood D, Barr S, Dawson RJ (2015) Optimized Spatial Planning to meet Urban Sustainability Objectives, Computers, Environment \& Urban Simulation, 54:154-164.

22. Deb, K., 2001, Multi-Objective Optimization using Evolutionary Algorithms, John Wiley \& Sons Ltd, Chichester.

23. Goldberg, D. E., 1989, Genetic Algorithms for Search, Optimization and Machine Learning, Addison-Wesley, Reading.

24. Mishra, K.K. and S. Harit, 2010, “A Fast Algorithm for Finding the Non Dominated Set in Multi objective Optimization", International Journal of Computer Applications, 1(25): 35-39.

25. ONS (Office of National Statistics), 2012, 2011 Census: Population Estimates for the United Kingdom, London.

26. Middlesbrough Council, 2012, Local Development Framework Core Strategy and Regeneration Development Plan Document: Housing Review Issues and Options Report, Middlesbrough, UK.

27. Middlesbrough Council, 2013, Local Development Framework Housing Review Preferred Options: Sustainability Appraisal, Middlesbrough, UK.

28. DCLG (Department for Communities and Local Government), 2003, The North East of England Plan Regional Spatial Strategy to 2021, The Stationery Office, London.

29. Melia, S., G. Parkhurst, and H. Barton, 2012, "The Paradox of Intensification", Journal of Transport Policy, 18(1), p. 46-52.

30. Carter, J. G. (2011). Climate change adaptation in European cities. Current Opinion in Environmental Sustainability, 3(3), 193-198. doi:10.1016/j.cosust.2010.12.015

31. DCLG (Department for Communities and Local Government) (2008). The North East of England Plan Regional Spatial Strategy to 2021. The Stationery Office, London. Retrieved from http://www.sunderland.gov.uk/CHttpHandler.ashx?id=136 $7 \& \mathrm{p}=0$

32. GLA (Greater London Authority) (2011). The London Plan: Spatial Development Plan. GLA: London.

33. American Planning Association. (2000). Policy Guide on Planning for Sustainability. New York. Retrieved from https://www.planning.org/policy/guides/pdf/sustainability. pdf
34. DCLG (2012). National Planning Policy Framework. Eland House: London. Retrieved from https://www.gov.uk/government/uploads/system/uploads/a ttachment_data/file/6077/2116950.pdf

35. Jenkins, G., J. Murphy, D. Sexton, J. Lowe, P. Jones and C. Kilsby, 2009, UK Climate Projections: Briefing report, Exeter, UK.

36. Burton A, V. Glenis, M.R. Jones and C.G. Kilsby, 2013, "Models of daily rainfall cross-correlation for the United Kingdom", Environmental Modelling and Software, (accepted for publication).

37. Kilsby C.G., P.D. Jones, A. Burton, A. Ford, H.J. Fowler, C. Harpham, P. James, A. Smith and R.L. Wilby, 2007, "A daily weather generator for use in climate change studies", Environmental Modelling and Software, 22(12): 1705-19.

38. Jones P.D., C.G. Kilsby, C. Harpham, V. Glenis and A. Burton, 2009, "UK Climate Projections science report: Projections of future daily climate for the UK from the Weather Generator", UK Climate Impacts Programme, London, UK.

39. Ewing, R. \& Cervero, R. (2010). Travel and the Built Environment. Journal of the American Planning Association, 76 (3), 265-94.

40. ONS (Office of National Statistics) (2012). 2011 Census: Population Estimates for the United Kingdom. London. 